\title{
Obesity and incidence of cancer: a large cohort study of over 145000 adults in Austria
}

\author{
K Rapp*, , J Schroeder ${ }^{2}$, J Klenk', S Stoehr', H Ulmer,4, H Concin ${ }^{4}$, G Diem ${ }^{4}$, W Oberaigner ${ }^{5}$ and SK Weiland' \\ 'Department of Epidemiology, University of Ulm, Helmholtzstraße 22, 8908 I Ulm, Germany; ' Department of Epidemiology, University of North Carolina, \\ Chapel Hill, NC 27599-7435, USA; ${ }^{3}$ Department of Medical Statistics, Informatics and Health Economics, Medical University, Innsbruck, Austria; ${ }^{4}$ Agency \\ for Preventive and Social Medicine, Rheinstraße 61, 6900 Bregenz, Austria; ${ }^{5}$ Cancer Registry of Tyrol, Department of Clinical Epidemiology of the Tyrolean \\ State Hospitals Ltd, Maximilianstraße 35, 6020 Innsbruck, Austria
}

We investigated the relation of overweight and obesity with cancer in a population-based cohort of more than 145000 Austrian adults over an average of 9.9 years. Incident cancers $(n=6241)$ were identified through the state cancer registry. Using Cox proportional-hazards models adjusted for smoking and occupation, increases in relative body weight in men were associated with colon cancer (hazard rate (HR) ratio 2.48; 95\% confidence interval $(\mathrm{Cl}): 1.15,5.39$ for body mass index $(\mathrm{BMI}) \geqslant 35 \mathrm{~kg} \mathrm{~m}^{-2}$ ) and pancreatic cancer $\left(\mathrm{HR} 2.34,95 \% \mathrm{Cl}\right.$ : I.17, 4.66 for $\mathrm{BMl}>30 \mathrm{~kg} \mathrm{~m}^{-2}$ ) compared to participants with normal weight (BMI I8.5$24.9 \mathrm{~kg} \mathrm{~m}^{-2}$ ). In women, there was a weak positive association between increasing BMI and all cancers combined, and strong associations with non-Hodgkin's lymphomas (HR 2.86, 95\% Cl: $1.49,5.49$ for BMl $\geqslant 30 \mathrm{~kg} \mathrm{~m}^{-2}$ ) and cancers of the uterine corpus (HR $3.93,95 \% \mathrm{Cl}: 2.35,6.56$ for BMI $\geqslant 35 \mathrm{~kg} \mathrm{~m}^{-2}$ ). Incidence of breast cancer was positively associated with high BMI only after age 65 years. These findings provide further evidence that overweight is associated with the incidence of several types of cancer.

British Journal of Cancer (2005) 93, 1062-1067. doi:10.1038/sj.bjc.6602819 www.bjcancer.com

Published online 18 October 2005

(c) 2005 Cancer Research UK

Keywords: obesity; breast cancer; colonic cancer; endometrial cancer; lymphoma; non-Hodgkin; pancreatic cancer

Overweight and obesity is an increasing health problem, not only for industrialised countries but also for most other parts of the world. This epidemic appears to be affecting all ages, including childhood (WHO, 2000). Prospective studies have observed an association between overweight and overall mortality (Lew and Garfinkel, 1979; Manson et al, 1995; Calle et al, 1999), and several adverse health consequences of elevated body weight are well established, including type II diabetes, hypertension and coronary heart disease (Must et al, 1999). Obesity has also been associated with cancer incidence and mortality, and positive associations between obesity and risks of specific cancers, including endometrial and kidney cancer, are widely accepted (Calle and Kaaks, 2004). Inconsistent evidence of associations between other cancers and body weight may be due in part to small sample sizes and misclassification of body weight in retrospective studies. The relation between body mass index (BMI) and incidence of different cancers as ascertained by population-based cancer registries has been investigated by few studies (Moller et al, 1994; Wolk et al, 2001). We conducted a prospective investigation of the association between overweight and the incidence of cancer (overall and specific types) using data from the Vorarlberg cancer registry and a population-based cohort of more than 145000 Austrian men and women followed for an average of nearly 10 years.

*Correspondence: Dr K Rapp; E-mail: kilian.rapp@medizin.uni-ulm.de Received 16 June 2005; revised 12 September 2005; accepted 19 September 2005; published online 18 October 2005

\section{MATERIALS AND METHODS}

\section{Study population}

The Vorarlberg Health Monitoring and Promotion Program (VHM\&PP) is carried out in Vorarlberg, the westernmost province of Austria. It is performed routinely by the Agency of Social and Preventive Medicine and covers all adults of the whole province. The screening examination takes place in the practice of local physicians; it includes a physical examination, a blood test and a consultation with a doctor. Enrolment is voluntary and costs are covered by the participant's (compulsory) health insurance. More than two-thirds of the adult population of the province (between the age of 35 and 54 years) participated and underwent at least one examination since the beginning of the programme in 1985 (Ulmer et al, 2004). The VHM\&PP has been described in detail previously (Ulmer et al, 2003).

Between 1985 and 2001, 167371 adult Vorarlberg residents were enrolled in the VHM\&PP Study Cohort after signing an informed consent to store and process personal data (height, weight, smoking and other factors). The current analysis was restricted to participants with complete data on height, weight and occupational group at enrolment. As in a previous study (Calle et al, 2003), participants with a baseline BMI $\left(\mathrm{kg} \mathrm{m}^{-2}\right)$ below normal (BMI $<18.5 \mathrm{~kg} \mathrm{~m}^{-2}, n=5053$ ) were excluded. In order to avoid an influence of cancer growth on body weight, participants were further excluded if they had been diagnosed with a malignant cancer prior to enrolment, or within 1 year following enrolment $(n=1831)$. Therefore, the first year of follow-up time was not 
Table I Characteristics of the VHM\&PP study cohort

\begin{tabular}{|c|c|c|c|}
\hline & Men & Women & All \\
\hline Eligible VHM\&PP participants $(N)^{a}$ & 67447 & 78484 & |4593| \\
\hline \multicolumn{4}{|l|}{ Age at entry (years) } \\
\hline Mean (s.d. $\left.{ }^{b}\right)$ & $41.78(14.47)$ & $42.48(15.66)$ & $42.16(15.12)$ \\
\hline Range & $18.66-93.03$ & $19.00-94.13$ & $18.66-94.13$ \\
\hline \multicolumn{4}{|l|}{ Years of follow-up } \\
\hline Mean (s.d. $\left.{ }^{b}\right)$ & $9.63(4.63)$ & $10.18(4.56)$ & $9.93(4.60)$ \\
\hline Range & $0.00-16.89$ & $0.00-16.84$ & $0.00-16.89$ \\
\hline Total person-years at risk & 649358 & 799122 & | 448480 \\
\hline \multicolumn{4}{|l|}{$B M I^{c}(\%)$} \\
\hline Normal: $18.5-24.9 \mathrm{~kg} \mathrm{~m}^{-2}$ & 50.47 & 62.86 & 57.13 \\
\hline Overweight: $25-29.9 \mathrm{~kg} \mathrm{~m}^{-2}$ & 40.05 & 25.60 & 32.28 \\
\hline Obese I: $30-34.9 \mathrm{~kg} \mathrm{~m}^{-2}$ & 8.23 & 8.55 & 8.40 \\
\hline Obese II and III: $\geqslant 35 \mathrm{~kg} \mathrm{~m}^{-2}$ & 1.25 & 2.99 & 2.19 \\
\hline \multicolumn{4}{|l|}{ Smoking (\%) } \\
\hline Current smoker & 29.99 & 20.78 & 25.03 \\
\hline Former smoker & 13.27 & 4.99 & 8.79 \\
\hline \multicolumn{4}{|l|}{ Occupational group ${ }^{\mathrm{d}}(\%)$} \\
\hline Blue collar & 37.29 & 38.09 & 37.72 \\
\hline White collar & 51.99 & 54.08 & 53.12 \\
\hline Self-employed & 10.72 & 7.82 & 9.16 \\
\hline Number of cancers & 3337 & 2904 & 6241 \\
\hline \multicolumn{4}{|l|}{ Age at cancer diagnosis (years) } \\
\hline Mean (s.d. ${ }^{b}$ ) & $65.34(11.49)$ & $62.88(\mid 3.21)$ & $64.20(12.38)$ \\
\hline Range & $22.87-95.69$ & $22.43-96.29$ & $22.43-96.29$ \\
\hline \multicolumn{4}{|c|}{ 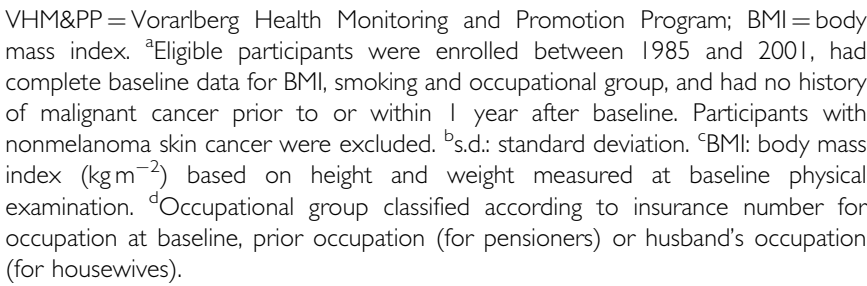 } \\
\hline
\end{tabular}

considered in the analysis and participants with a follow-up period of less than 1 year $(n=5528)$ were excluded. To evaluate the sensitivity of our analyses to this 1-year exclusion, we also repeated the analyses with a 3-year exclusion. The final study cohort consisted of 67447 men and 78484 women, with mean age at study entry of 41.8 years for men and 42.5 years for women (Table 1 ). The average time of follow-up was nearly 10 years, with a total of 1.45 million person-years. By the end of the total observation period of 17 years, 6241 incident cancers (other than nonmelanoma skin cancer) had been diagnosed (Table 1).

\section{Body mass index}

Baseline height and weight were recorded by medical staff at enrolment during the VHM\&PP physical examination. BMI was classified according to World Health Organisation guidelines as normal $\left(18.50-24.99 \mathrm{~kg} \mathrm{~m}^{-2}\right)$, overweight $\left(25.00-29.99 \mathrm{~kg} \mathrm{~m}^{-2}\right)$, obese class I $\left(30.00-34.99 \mathrm{~kg} \mathrm{~m}^{-2}\right)$, and obese class II and III $\left(\geqslant 35.00 \mathrm{~kg} \mathrm{~m}^{-2}\right)$ (2000). Normal BMI was the reference category for all analyses, and obesity categories were combined when necessary to ensure a minimum of five cancer outcomes in each exposure group.

\section{Covariates}

Associations were adjusted for smoking by including variables for current smoking and former smoking in the model, with the reference group being never smokers. Persons with missing smoking values were classified as never smokers because baseline questionnaire data did not differentiate between never-smokers and participants with missing values. However, smoking information from follow-up visits was available to validate the baseline smoking status of more than $70 \%$ of study participants. Occupational group (blue collar, white collar or self-employed) was determined by the insurance number of participants and was included in the models as a surrogate measure of socioeconomic status. Participants who were retired at baseline were classified according to their former occupation, and housewives according to their husband's occupation.

\section{End points}

Between 1985 and 2002, incident invasive cancers were identified by the Vorarlberg cancer registry, which is accepted for publication by the International Agency for Research on Cancer (IARC) since 1993 (Parkin et al, 2003). The proportion of cancers discovered by death certificate only (DCO) in the Vorarlberg registry for cases diagnosed between 1993 and 1997 was 7\% for men and 9\% for women (Oberaigner et al, 2003), and for cases diagnosed between 1998 and 2002 about 5\% in both sexes (W Oberaigner, personal communication, Cancer Registry of Tyrol). Nearly all cancers were histologically verified and coded according to the ninth revision of the International Classification of Diseases (ICD-9). Cohort data were linked with the Vorarlberg Death Index to identify deaths among cohort members to calculate personyears at risk.

\section{Statistical analysis}

We used Cox proportional-hazards models to compute hazard rate ratios (HR) and 95\% confidence intervals (95\% CI) for overweight and obesity relative to normal BMI, adjusted for smoking and occupational group at baseline. The models included age (in single years) in the strata statement. In tests of linear trend by BMI, the median value for BMI within each interval was entered in a regression model, and the significance of the term tested by the Wald's $\chi^{2}$ test. All calculations were carried out with SAS version 8.2 software.

All analyses were performed separately for men and women. Analyses on specific cancers were restricted to those types of cancer with at least 50 cases in men or women.

\section{RESULTS}

The study cohort consisted of 67447 men and 78484 women (Table 1). In men, positive linear trends in cancer incidence with increasing BMI were observed for colon and pancreatic cancer (Table 2). In comparison to men with normal weight, the hazard ratios for colon cancer were 1.56 (95\% CI: 1.06, 2.30) for men with BMI $30.0-34.99 \mathrm{~kg} \mathrm{~m}^{-2}$, and $2.48(1.15,5.39)$ for BMI $35.0 \mathrm{~kg} \mathrm{~m}^{-2}$ or more. The hazard ratios for men with BMI of at least $30.0 \mathrm{~kg} \mathrm{~m}^{-2}$ were for rectal cancer $1.66(1.00,2.73)$ and for pancreatic cancer $2.34(1.17,4.66)$. Nonsignificant positive associations were found for kidney and liver cancers.

In women, there was a weak positive association between BMI and all cancers (Table 3). Endometrial (uterine corpus) cancer was strongly associated with obesity class I (hazard ratio 2.13 (1.38, $3.27)$ ) and obesity class II and III (hazard ratio $3.93(2.35,6.56))$ in comparison to normal weight. Furthermore, a positive association was found between obesity and the incidence of non-Hodgkin's lymphomas (NHL) (hazard ratio $2.86(1.49,5.49)$, with a BMI of at least $30.0 \mathrm{~kg} \mathrm{~m}^{-2}$ ). Kidney cancer was associated with overweight, though not statistically significant. In contrast to men, BMI was not associated with colon or rectal cancer in women. 
Table 2 Estimated HR and 95\% Cl for incident cancers diagnosed among male participants in the VHM\&PP Study Cohort I985-200I, according to BM at enrolment

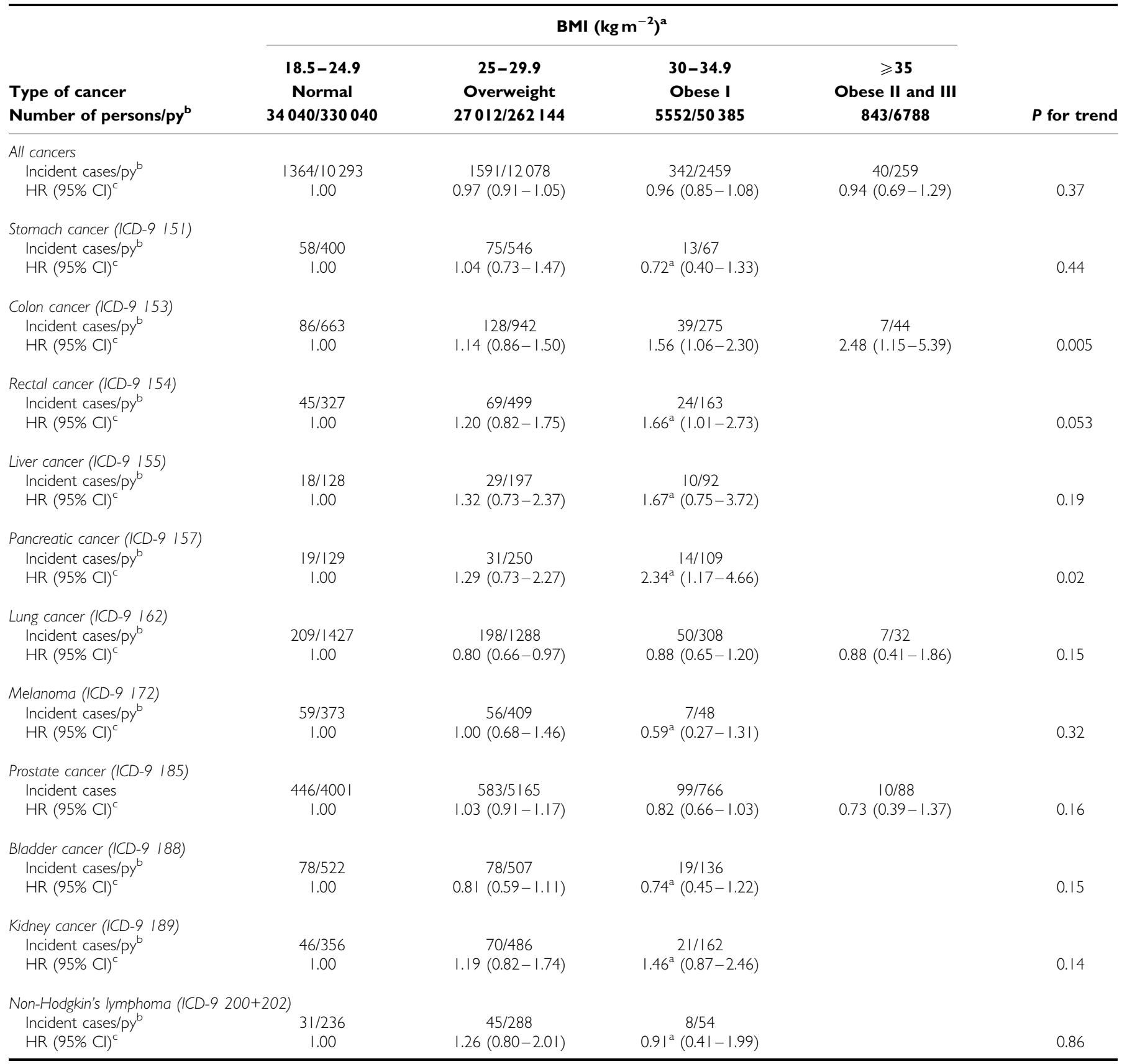

There was little evidence of an association between breast cancer and BMI overall. However, breast cancer diagnosed in women aged 65 years or older was positively associated with BMI (hazard ratios $1.48(1.12,1.95)$ for obesity class I and $1.29(0.79,2.11)$ for obesity class II and III; $P$ for trend 0.02).

All associations that were statistically significant after exclusion of the first year following entry into the study remained unchanged in terms of statistical significance when reanalysed excluding the first 3 years.

\section{DISCUSSION}

The major strengths of our study are the prospective design, the large number of subjects, the coverage of incident cases and the length of follow-up. The population of Vorarlberg is culturally and ethnically rather homogenous, with more than $90 \%$ of Austrian origin (Ulmer et al, 2003). Body mass index was based on height and weight measured at initial physical examination. Incident cancers were ascertained by the population-based cancer registry 
Table 3 Estimated $\mathrm{HR}$ and $95 \% \mathrm{Cl}$ for incident cancers diagnosed among female participants in the VHM\&PP Study Cohort I985-200I, according to $\mathrm{BMI}$ at enrolment

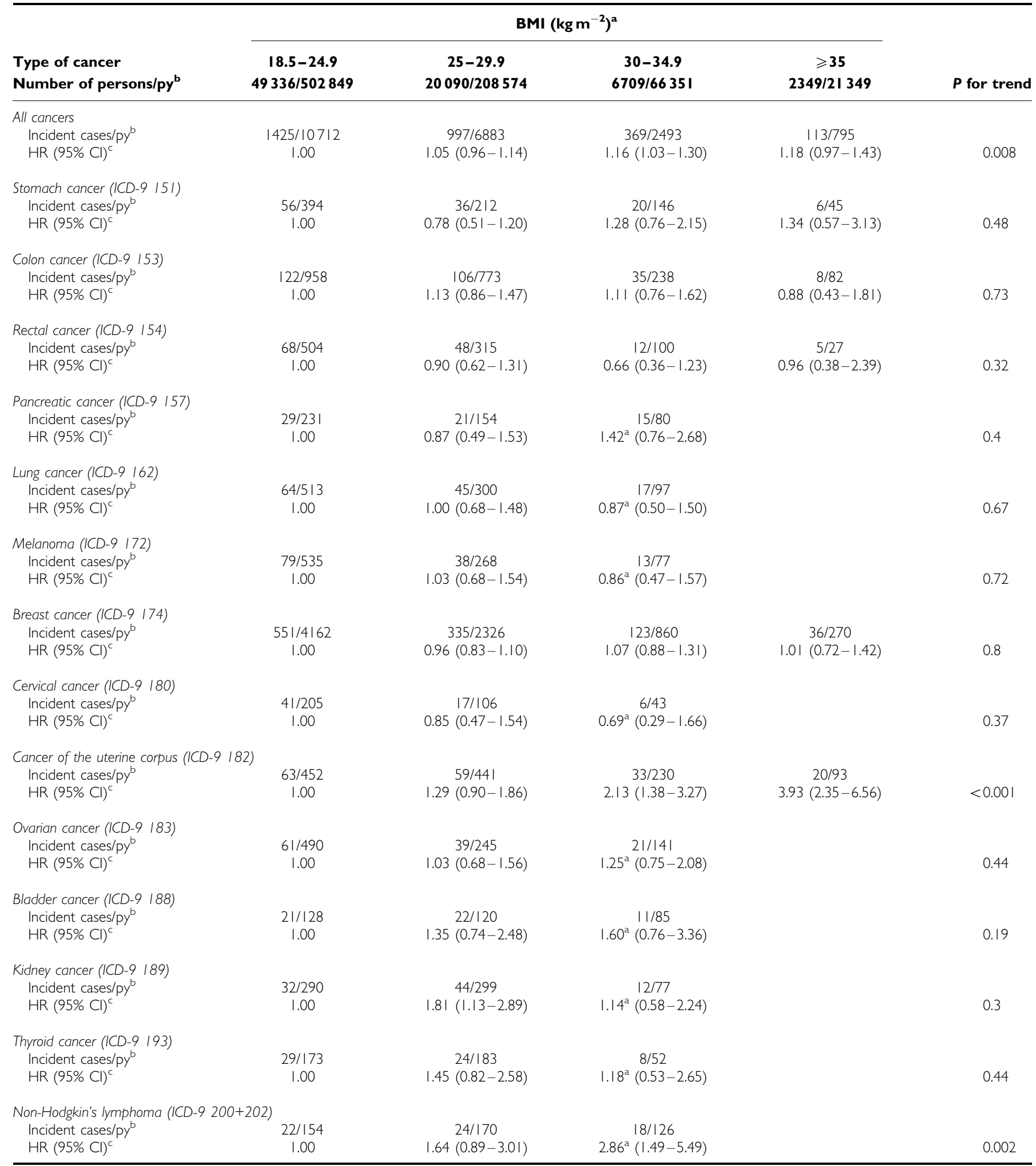

VHM\&PP = Vorarlberg Health Monitoring and Promotion Program; HR = hazards ratio; $\mathrm{Cl}=$ confidence interval; ICD = International Classification of Diseases; $\mathrm{BMI}=$ body mass index. ${ }^{a}$ Obese categories (class I and class II and III) were combined as needed to ensure at least five cases in each. ${ }^{b}$ Person-years. ${ }^{C}$ The Cox proportional-hazards model was stratified according to age at enrolment (in years) and adjusted for smoking status and occupational group. 
and nearly all histologically confirmed; the likelihood of exposure and outcome misclassification was therefore low.

The limitations of our study include that, despite the overall size of the cohort, some cancers of interest (for example, oesophageal adenocarcinoma or gallbladder cancer) could not be evaluated due to small numbers of cases. In addition, the prevalence of obesity in our cohort was relatively low. Consequently the power to examine extreme levels of obesity, particularly in association with less common cancers, was limited. The high proportion of neversmoking patients with lung cancer $(31 \%)$ suggests that there was some misclassification of smoking status, although this would probably attenuate the relation between BMI and most cancers, given the inverse association between smoking and body weight. We used occupational group as a rough surrogate for socioeconomic status, but were unable to account for such potentially confounding factors as alcohol consumption or physical activity.

Our finding of an association between BMI and both colon and rectum cancers in men supports earlier observations (Lew and Garfinkel, 1979; Giovannucci et al, 1995; Pan et al, 2004; Samanic et al, 2004) and may be due to the growth-promoting effects of insulin and insulin-like growth factor (IGF-1), both increased in obesity (Calle and Kaaks, 2004). Our failure to find an association between BMI and colon cancer in women also agrees with other studies (Phillips and Snowdon, 1985; Shimizu et al, 2003), and may be related to the protective effects of elevated oestrogen levels in overweight postmenopausal women, as found by studies of exogenous hormone therapy in such women (Calle et al, 1995; Newcomb and Storer, 1995).

We observed a positive association between pancreatic cancer and overweight or obesity in men, and to a lesser extent in women. Other studies have been inconsistent in this connection (Berrington et al, 2003). As with colon cancer, relations between pancreatic cancer and BMI have been attributed to the growth-promoting effects of elevated insulin and IGFs secondary to obesity (Takeda and Escribano, 1991), although the carcinogenic effects of insulin have also been proposed to explain positive associations with abnormal glucose metabolism (Gapstur et al, 2000) or diabetes mellitus (Everhart and Wright, 1995).

In line with previous reports (Yuan et al, 1998; Chow et al, 2000), we observed a positive relation between BMI and incidence of kidney cancer in men, which, however, did not reach statistical significance. In women, our findings showed a positive association between kidney cancer and overweight, but not obesity. Our finding of a positive association between BMI and breast cancer only among women at the age of 65 years or older is consistent with previous reports (Hunter and Willett, 1993).

A relation between endometrial cancer (cancer of the uterine corpus) and overweight is widely accepted (Calle and Kaaks, 2004), and it was found that this in very obese women (BMI $\geqslant 35 \mathrm{~kg} \mathrm{~m}^{-2}$ ) were more likely to be diagnosed with endometrial cancer than women with normal BMI at baseline (HR 3.93, 95\% CI: 2.35, 6.56). A crucial pathway seems to be oestrogens that are not counterbalanced by progesterone (the 'unopposed oestrogen' hypothesis) (Kaaks et al, 2002). Anovulatory cycles in obese premenopausal women may contribute to a deficiency of progesterone, which normally opposes the mitogenic effect of oestrogen on the endometrial mucosa.

We also observed a strong positive association between BMI and NHL among women, but not men. Previous prospective studies of overweight and NHL have been inconsistent (Moller et al, 1994; Wolk et al, 2001; Cerhan et al, 2002; Calle et al, 2003; Samanic et al, 2004), though several case-control studies have reported an association between overweight and NHL in both sexes (Holly et al, 1999; Pan et al, 2004; Skibola et al, 2004). The incidence of NHL has increased in many parts of the world (Muller et al, 2005) and obesity might be a contributing factor.

As previously reported (Calle and Kaaks, 2004), liver cancer showed a (non-significant) association with BMI in men with point estimates clearly above one, but based on only 57 cases; there were too few cases of liver cancer for a separate analysis in women.

Many studies have examined relations between overweight and single cancer outcomes. Few prospective studies examined the influence of overweight on a range of specific cancers both in men and women (Lew and Garfinkel, 1979; Moller et al, 1994; Wolk et al, 2001; Calle et al, 2003). Our study of a large Austrian cohort provides additional support from another population for associations between BMI and the incidence of colon, rectal and pancreatic cancer, and to a lesser extent of kidney and liver cancer in men, and with endometrial cancer, postmenopausal breast cancer and NHL in women.

\section{ACKNOWLEDGEMENTS}

We thank all physicians participating in the Vorarlberg Health Monitoring and Promotion Program (VHM\&PP) for conducting the examinations and providing the data. The VHM\&PP is supported by the State of Vorarlberg, Austria.

\section{REFERENCES}

Berrington DG, Sweetland S, Spencer E (2003) A meta-analysis of obesity and the risk of pancreatic cancer. Br J Cancer 89: 519-523

Calle EE, Kaaks R (2004) Overweight, obesity and cancer: epidemiological evidence and proposed mechanisms. Nat Rev Cancer 4: 579-591

Calle EE, Miracle-McMahill HL, Thun MJ, Heath Jr CW (1995) Estrogen replacement therapy and risk of fatal colon cancer in a prospective cohort of postmenopausal women. J Natl Cancer Inst 87: 517 - 523

Calle EE, Rodriguez C, Walker-Thurmond K, Thun MJ (2003) Overweight, obesity, and mortality from cancer in a prospectively studied cohort of U.S. adults. $N$ Engl J Med 348: $1625-1638$

Calle EE, Thun MJ, Petrelli JM, Rodriguez C, Heath Jr CW (1999) Bodymass index and mortality in a prospective cohort of U.S. adults. $N$ Engl J Med 341: $1097-1105$

Cerhan JR, Janney CA, Vachon CM, Habermann TM, Kay NE, Potter JD, Sellers TA, Folsom AR (2002) Anthropometric characteristics, physical activity, and risk of non-Hodgkin's lymphoma subtypes and B-cell chronic lymphocytic leukemia: a prospective study. Am J Epidemiol 156: $527-535$

Chow WH, Gridley G, Fraumeni Jr JF, Jarvholm B (2000) Obesity, hypertension, and the risk of kidney cancer in men. $N$ Engl J Med 343: $1305-1311$
Everhart J, Wright D (1995) Diabetes mellitus as a risk factor for pancreatic cancer. A meta-analysis. JAMA 273: 1605-1609

Gapstur SM, Gann PH, Lowe W, Liu K, Colangelo L, Dyer A (2000) Abnormal glucose metabolism and pancreatic cancer mortality. JAMA 283: $2552-2558$

Giovannucci E, Ascherio A, Rimm EB, Colditz GA, Stampfer MJ, Willett WC (1995) Physical activity, obesity, and risk for colon cancer and adenoma in men. Ann Intern Med 122: 327-334

Holly EA, Lele C, Bracci PM, McGrath MS (1999) Case-control study of non-Hodgkin's lymphoma among women and heterosexual men in the San Francisco Bay Area, California. Am J Epidemiol 150: 375-389

Hunter DJ, Willett WC (1993) Diet, body size, and breast cancer. Epidemiol Rev 15: $110-132$

Kaaks R, Lukanova A, Kurzer MS (2002) Obesity, endogenous hormones, and endometrial cancer risk: a synthetic review. Cancer Epidemiol Biomarkers Prev 11: $1531-1543$

Lew EA, Garfinkel L (1979) Variations in mortality by weight among 750000 men and women. J Chronic Dis 32: 563-576

Manson JE, Willett WC, Stampfer MJ, Colditz GA, Hunter DJ, Hankinson SE, Hennekens CH, Speizer FE (1995) Body weight and mortality among women. $N$ Engl J Med 333: 677-685 
Moller H, Mellemgaard A, Lindvig K, Olsen JH (1994) Obesity and cancer risk: a Danish record-linkage study. Eur J Cancer 30A: $344-350$

Muller AM, Ihorst G, Mertelsmann R, Engelhardt M (2005) Epidemiology of non-Hodgkin's lymphoma (NHL): trends, geographic distribution, and etiology. Ann Hematol 84: 1-12

Must A, Spadano J, Coakley EH, Field AE, Colditz G, Dietz WH (1999) The disease burden associated with overweight and obesity. JAMA 282: $1523-1529$

Newcomb PA, Storer BE (1995) Postmenopausal hormone use and risk of large-bowel cancer. J Natl Cancer Inst 87: 1067-1071

Oberaigner W, Concin H, Mathis G (2003) aks Report, Vol 2; www.aks.or.at/ berichte

Pan SY, Johnson KC, Ugnat AM, Wen SW, Mao Y (2004) Association of obesity and cancer risk in Canada. Am J Epidemiol 159: 259-268

Parkin DM, Whelan SL, Ferlay J, Teppo L, Thomas DB, all at the International Agency for Research on Cancer, Lyon, France (2003) Cancer incidence in five continents. Report, Vol VIII, ISBN 9283221559

Phillips RL, Snowdon DA (1985) Dietary relationships with fatal colorectal cancer among Seventh-Day Adventists. J Natl Cancer Inst 74: $307-317$

Samanic C, Gridley G, Chow WH, Lubin J, Hoover RN, Fraumeni Jr JF (2004) Obesity and cancer risk among white and black United States veterans. Cancer Causes Control 15: 35-43

Shimizu N, Nagata C, Shimizu H, Kametani M, Takeyama N, Ohnuma T, Matsushita S (2003) Height, weight, and alcohol consumption in relation to the risk of colorectal cancer in Japan: a prospective study. $\mathrm{Br} \mathrm{J}$ Cancer 88: $1038-1043$

Skibola CF, Holly EA, Forrest MS, Hubbard A, Bracci PM, Skibola DR, Hegedus C, Smith MT (2004) Body mass index, leptin and leptin receptor polymorphisms, and non-Hodgkin lymphoma. Cancer Epidemiol Biomarkers Prev 13: $779-786$

Takeda Y, Escribano MJ (1991) Effects of insulin and somatostatin on the growth and the colony formation of two human pancreatic cancer cell lines. J Cancer Res Clin Oncol 117: 416-420

Ulmer H, Kelleher C, Diem G, Concin H (2003) Long-term tracking of cardiovascular risk factors among men and women in a large populationbased health system: the Vorarlberg Health Monitoring \& Promotion Programme. Eur Heart J 24: $1004-1013$

Ulmer H, Kelleher C, Diem G, Concin H (2004) Why Eve is not Adam: prospective follow-up in 149650 women and men of cholesterol and other risk factors related to cardiovascular and all-cause mortality. J Women's Health (Larchmt) 13: $41-53$

WHO (2000) Obesity: preventing and managing the global epidemic. Report of a WHO consultation. World Health Organ Tech Rep Ser 894: i- 253

Wolk A, Gridley G, Svensson M, Nyren O, McLaughlin JK, Fraumeni JF, Adam HO (2001) A prospective study of obesity and cancer risk (Sweden). Cancer Causes Control 12: 13-21

Yuan JM, Castelao JE, Gago-Dominguez M, Ross RK, Yu MC (1998) Hypertension, obesity and their medications in relation to renal cell carcinoma. Br J Cancer 77: $1508-1513$ 